\title{
BMJ Open Development and validation of Australian aphasia rehabilitation best practice statements using the RAND/ UCLA appropriateness method
}

\author{
Emma Power, ${ }^{1,2}$ Emma Thomas, ${ }^{2,3}$ Linda Worrall,,3 Miranda Rose, ${ }^{2,4}$ \\ Leanne Togher, ${ }^{1,2}$ Lyndsey Nickels, ${ }^{2,5}$ Deborah Hersh, ${ }^{2,6}$ Erin Godecke, ${ }^{2,6}$ \\ Robyn O'Halloran, ${ }^{2,4}$ Sue Lamont, ${ }^{7}$ Claire O'Connor, ${ }^{8}$ Kim Clarke ${ }^{9}$
}

To cite: Power E, Thomas E, Worrall L, et al. Development and validation of Australian aphasia rehabilitation best practice statements using the RAND/UCLA appropriateness method. BMJ Open 2015;5: e007641. doi:10.1136/ bmjopen-2015-007641

- Prepublication history and additional material is available. To view please visit the journal (http://dx.doi.org/ 10.1136/bmjopen-2015007641).

Received 11 January 2015 Revised 5 May 2015 Accepted 3 June 2015

CrossMark

For numbered affiliations see end of article.

\section{Correspondence to}

Dr Emma Power;

emma.power@sydney.edu.au

\section{ABSTRACT}

Objectives: To develop and validate a national set of best practice statements for use in post-stroke aphasia rehabilitation.

Design: Literature review and statement validation using the RAND/UCLA Appropriateness Method (RAM).

Participants: A national Community of Practice of over 250 speech pathologists, researchers, consumers and policymakers developed a framework consisting of eight areas of care in aphasia rehabilitation. This framework provided the structure for the development of a care pathway containing aphasia rehabilitation best practice statements. Nine speech pathologists with expertise in aphasia rehabilitation participated in two rounds of RAND/UCLA appropriateness ratings of the statements. Panellists consisted of researchers, service managers, clinicians and policymakers.

Main outcome measures: Statements that achieved a high level of agreement and an overall median score of 7-9 on a nine-point scale were rated as 'appropriate'.

Results: 74 best practice statements were extracted from the literature and rated across eight areas of care (eg, receiving the right referrals, providing intervention). At the end of Round 1, 71 of the 74 statements were rated as appropriate, no statements were rated as inappropriate, and three statements were rated as uncertain. All 74 statements were then rated again in the face-to-face second round. 16 statements were added through splitting existing items or adding new statements. Seven statements were deleted leaving 83 statements. Agreement was reached for 82 of the final 83 statements.

Conclusions: This national set of 82 best practice statements across eight care areas for the rehabilitation of people with aphasia is the first to be validated by an expert panel. These statements form a crucial component of the Australian Aphasia Rehabilitation Pathway (AARP) (http://www.aphasiapathway.com.au) and provide the basis for more consistent implementation of evidence-based practice in stroke rehabilitation.

\section{Strengths and limitations of this study}

- There is limited guidance for health professionals working with the complex condition of aphasia to implement best practice across the continuum of care.

- The aim of this study was to develop and validate a set of best practice statements for use in post-stroke aphasia rehabilitation.

- An aphasia rehabilitation Community of Practice developed eight areas of care that provided the framework for the development of an initial 74 best practice statements. These statements were then validated using the RAND/UCLA Appropriateness Method in two rounds of ratings with nine panel members.

- During the rating, items were added, divided or deleted so that there was panel agreement on a final set of 82 best practice statements over eight domains of care. These evidence-based and expert endorsed care standards form part of the Australian Aphasia Rehabilitation Pathway (AARP), and have been formulated into a dynamic webbased implementation tool with increasing attention to care standards for culturally and linguistically diverse, and indigenous populations.

- The literature reviews may not be exhaustive given the continuing development of the published evidence. The best practice statements may require some adaptation for other regions; however, the majority of the data should be common and internationally applicable. This process sets a benchmark for the development and dissemination of best practice post-stroke aphasia rehabilitation statements to other areas of practice where research evidence is in its foundational stage.

\section{INTRODUCTION}

Aphasia is an acquired neurological disorder of language processing that affects speaking, listening, reading, writing and gesture. ${ }^{1}$ Approximately $30-35 \%$ of stroke survivors 
have aphasia on discharge from hospital following stroke, ${ }^{23}$ with the prevalence of speech (dysarthria) and language (aphasia) disability 6 months after stroke reported as $30-50 / 100000 .{ }^{4}$ People with aphasia have higher healthcare costs $(8.5 \%$ or $\$ 1700$ attributable cost) and longer length of stays in hospital $(6.5 \%)$ compared with stroke survivors without aphasia. ${ }^{5}$ People with stroke-related aphasia may require additional services to address their communication disability in hospital and also during community life, and such services might reduce their length of length of stay or incidence of adverse events. ${ }^{6}{ }^{7}$ However, the management of swallowing disorders (dysphagia) may be prioritised over aphasia services in acute hospital settings due to inadequate staffing ratios and lack of appropriate therapy space/resources. ${ }^{8} 9$ Additionally, people with aphasia have poor long-term outcomes after stroke, including consequences such as social isolation, depression and poor quality of life for themselves and their family members. ${ }^{410-13}$ As a chronic disability, aphasia generates a number of long-term service needs, including therapy to enable functional and socially relevant communication. ${ }^{14}$ Provision of quality, efficient, evidence-based care is critical for people with aphasia, their families, and healthcare systems.

Stroke clinicians and teams need to make daily decisions about the management of people with aphasia from the acute phase through to community-based care. However, a variety of challenges exist to the implementation of best practice in aphasia rehabilitation. Using the AGREEII and ADAPTE guideline appraisal tools, Rohde et $a l^{15}$ documented a significant lack of high quality, comprehensive guidance for clinicians working with people with aphasia. Most recommendations identified were included within broader stroke guidelines and frequently lacked details on management of aphasia. The Australian National Stroke Foundation Clinical Guidelines for Stroke Management ${ }^{16}$ were identified as high-quality guidelines. These guidelines contain 11 items that are focused specifically on aphasia from screening, goal setting, provision of health information, therapy and counselling to communication partner training for family/carers. Despite the availability of these guidelines and the fact that their use has been shown to result in improved patient outcomes, ${ }^{17}$ documented evidence to practice gaps continue to exist. For example, in provision of health information, only $56 \%$ of a sample of 170 Australian hospitals provided at least 'some' information in tailored, 'aphasia friendly' formats to people with aphasia as the guidelines recommend. ${ }^{18}$ Additionally, some people with aphasia are not receiving treatment, ${ }^{19}$ despite a recent Cochrane review that found that aphasia therapy was generally effective. ${ }^{20}$ While the above two examples are centred on Australian stroke rehabilitation practice, evidence to practice gaps in stroke rehabilitation have also been documented internationally. ${ }^{21}$

Clinicians report that implementation of best practice is challenging because recommendations are often too broad and the evidence-base is limited in some areas. ${ }^{92}$ For example, while the Cochrane aphasia rehabilitation review $^{20}$ concluded that therapy was generally effective, an additional difficulty for clinicians is that there is still insufficient evidence to indicate the best approach to provision of aphasia therapy for specific individuals with aphasia. Clinicians report they require more in-depth information and research and accompanying resources (eg, standardised clinical resources such as aphasia friendly information handouts) to bridge the evidence to practice gap. ${ }^{9}{ }^{22}$ Evidence to practice gaps are of concern as consumers report a lack of consistency in the provision of aphasia care and difficulty accessing communication therapy services, especially in the chronic phase. ${ }^{1423}$ Consumers also emphasise the importance of the rehabilitation journey and the need for a comprehensive road map to understand what to expect at different phases of their recovery. ${ }^{14} 23$

The Centre for Clinical Research Excellence (CCRE) in Aphasia Rehabilitation is an Australian research centre that was funded for 5 years by the Australian National Health and Medical Research Council (NHMRC). The CCRE in Aphasia Rehabilitation drove a national collaborative effort to enhance the quality and consistency of rehabilitation care provided to people with aphasia. To address the above issues of a lack of a detailed road map, comprehensive recommendations and accessible implementation resources, the CCRE in Aphasia Rehabilitation developed the Australian Aphasia Rehabilitation Pathway (AARP). ${ }^{24}$ This care pathway was developed to provide the basis for a road map containing important domains of $\operatorname{care}^{25} 26$ and was populated with detailed best practice statements (BPS) for each domain of the pathway. The mode of delivery of the AARP is a web-based dynamic tool that contains resources to assist with implementing each of the BPS recommendations. ${ }^{24}$ BPS are a recent development and intended to guide practice and promote a consistent, cohesive and achievable approach to care. ${ }^{27}$ These address an area of care where there is variation in practice due to limited robust evidence; the BPS attempt to incorporate professional consensus in the absence of a rigorous evidence base. ${ }^{27}$

One method of developing BPS is the RAND/UCLA Appropriateness Method (RAM). ${ }^{28}$ The RAM consists of the development and validation of quality indicators through a literature review and a two-round modifiedDelphi method with a panel of experts. ${ }^{28}$ The RAM has been used to develop validated, expert endorsed indicators in a wide range of fields, including paediatric traumatic brain injury rehabilitation, ${ }^{29}$ osteoarthritis ${ }^{30}$ and pharmacy. ${ }^{31}$ The process has been particularly recommended for areas of practice with an emerging evidence base because it seeks to combine both research (literature review) and clinical evidence (expert panel opinion). ${ }^{28}$ The aim of this study was to develop a comprehensive set of evidence-based, expert endorsed BPS for post-stroke aphasia rehabilitation utilising the RAM. 


\section{METHOD}

\section{Design}

We utilised the $\mathrm{RAM}^{22}$ to develop and validate the Australian Aphasia Rehabilitation Best Practice Statements. The RAM consists of a literature review and development of a list of 'indications', which we termed best practice statements. These statements were then rated for their degree of appropriateness by an expert panel in two rounds using a modified Delphi technique. The RAM approach has produced results that are valid ${ }^{32}$ and reliable. ${ }^{28}$ An overview of the process involved in developing and validating the RAM statements is found in figure 1, while a detailed timeline of processing and events can be found on the AARP website (http://www. aphasiapathway.com.au/flux-content/aarp/pdf/AustralianAphasia-Rehabilitation-Pathway-RAM-Timeline.pdf). The first round of ratings was conducted via email, while the second round of ratings was conducted face-to-face. The inclusion of a face-to-face round has been described as advantageous compared with traditional Delphi methods because it allows for greater opportunities for discussion and clarification of statement wording and evidence. ${ }^{31}$

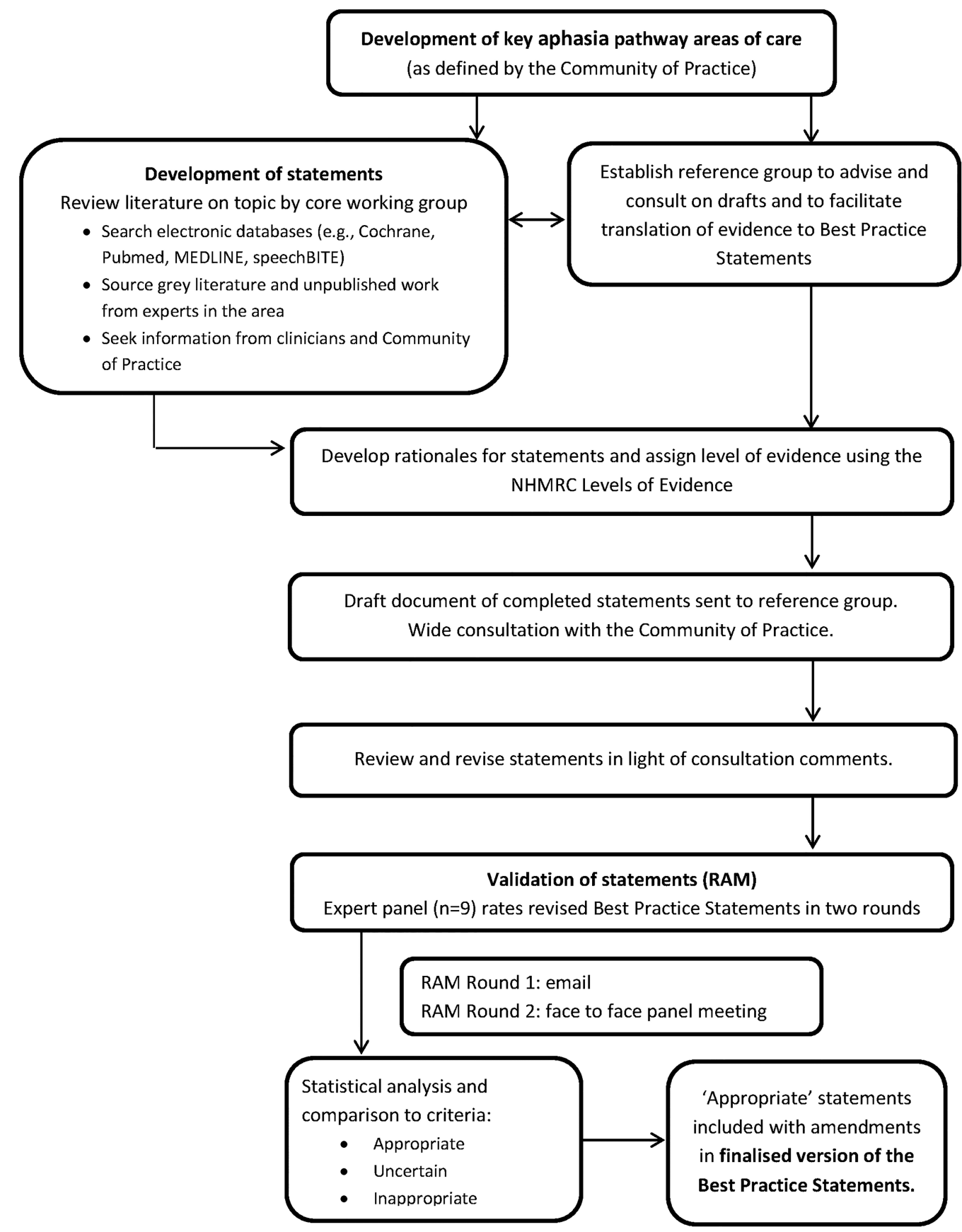

Figure 1 Overview of RAND/UCLA process as applied to the development of the Australian Aphasia Rehabilitation Best Practice Statements (adapted from Fitch et $a^{28}$ and NHS Quality Improvement Scotland). ${ }^{27} \mathrm{NHMRC}$, National Health and Medical Research Council; RAM, RAND/UCLA Appropriateness Method. 


\section{Development of best practice statements}

In developing and organising the statements, we were guided by eight overarching areas of care developed through a national consultative programme with the CCRE in Aphasia Rehabilitation Community of Practice (CoP). ${ }^{34}$ The CoP consisted of over 250 aphasia clinicians and managers, researchers, people with aphasia (Australian Aphasia Association) and policymakers (National Stroke Foundation) who were collectively interested in aphasia care, policy and practice. The eight areas of care were developed through an iterative process that occurred through face-to-face workshops, teleconferences, written feedback using Google Docs (a web-based word processing programme) and review of the research literature on consumer (patient and family) experiences with their care and goal setting. ${ }^{241423}$ The agreed areas of care were: (1) receiving the right referrals, (2) optimising initial contact, (3) setting goals and measuring outcomes, (4) assessing, (5) providing intervention, (6) enhancing the communicative environment, (7) enhancing personal factors, (8) planning for transitions and discharges.

From January to August 2013, a core team of researchers from the CCRE in Aphasia Rehabilitation (see table 1) conducted multiple literature reviews to provide a synthesis of the evidence-base for each area of care identified (see figure 1, earlier). The synthesis, construction and refinement of the BPS was an iterative, cyclical process. Within each content area, research questions were created by the project manager in conjunction with the core literature review group. Initially, the literature was searched for secondary level evidence. We accessed available guidelines that were identified by Rohde $e t a l^{15}$ as being of high quality, including the Australian Clinical Guidelines for Stroke Management. ${ }^{16}$ Other major sources of secondary evidence were: Trip Database (http://www.tripdatabase.com); Evidence Based Reviews of Stroke Rehabilitation (http://www.ebrsr.com); the Cochrane Library and American Speech and Hearing Association's Evidence Maps: Aphasia (http://ncepmaps. org/aphasia/tx/). We also accessed systematic reviews and then conducted a manual search of their bibliographies. If no secondary evidence was available, search terms were then developed for each area of care and applied to the following databases: The Cochrane Library (2005-2013), CINAHL (1981-2013), Medline (1946-2013), Pubmed (1948-2013), speechBITE (19562013) and Google Scholar (2009-2013). All quantitative research designs were included (eg, systematic reviews, randomised controlled trials, cohort studies, single case experimental designs) as well as qualitative research studies. Additional experts in each care area (see table 1) were contacted and requested to provide any applicable literature (both published literature and grey literature). Evidence was synthesised by the project manager and sent back to key experts and the CCRE executive team (core group) via email. Limited published literature was identified for Section 6 (Enhancing the Communicative Environment) and Section 7 (Enhancing Personal
Factors). Therefore greater input was required from experts. One CCRE researcher with specialist expertise working with Aboriginal and Torres Strait Islander people led a team to prepare the literature review and development of BPS in this area. Likewise, a CCRE postdoctoral researcher led the development of the BPS in regards to Culturally and Linguistically Diverse (CALD) populations.

The quantitative literature was graded according to the NHMRC Levels of Evidence and Grades of Recommendation. $^{35}$ This grading system was chosen because it aligns with the Australian Clinical Guidelines for Stroke Management ${ }^{10}$ and is the system endorsed by the Australian NHMRC peak body. As the NHMRC levels of evidence do not include a level for every type of study design, single case experimental designs studies were assigned a grading of IV, and the qualitative literature, if used to support a best practice statement, was listed as 'Qual'. It must be emphasised that this system only allows for the level of study design to be assessed, which is different to the grade of evidence. The grade of evidence (eg, A, B, C, D) takes into account the level of evidence along with evidence quantity, quality, consistency, clinical impact, generalizability and applicability. This additional step was not feasible at the time of the development of the BPS. Qualitative studies were not rated due to the lack of current consensus methods for grading of qualitative studies; however, only studies that were judged to be rigorous were included. Where expert opinion was utilised as the evidence for a statement, we followed the procedures in the Australian Clinical Guidelines for Stroke Management ${ }^{16}$ and labelled the level of evidence as a 'Good Practice Point' (GPP).

All 250 members of the $\mathrm{CoP}$ were invited to provide feedback on the synthesis of each area. This process has been previously described (see ${ }^{24}$ http://www.aphasia pathway.com.au/flux-content/aarp/Thomas-KTEaphasiapathway-JCPSLP-2014.pdf). Briefly, of the CoP members, a group of CCRE researchers $(n=25)$ and clinical affiliates $(n=45)$ expressed interest in providing regular feedback and formed the constituents of a feedback mail group. The core CCRE Aphasia Rehabilitation working group then translated the evidence into a list of BPS and additional input was sought from researchers who had specific expertise in each of the areas of care (see additional experts listed in table 1). Further feedback was then obtained on the initial draft of statements from the feedback mail group using an online programme 'Google Documents'. Feedback from the CoP in the refinement of the BPS was mostly provided by CoP speech pathologists. Two representatives of the Australian Aphasia Association provided consumer feedback throughout the process. However, they had most input for the workshops that established the areas of care rather than for the detailed refinement of the BPS. Development of the specific sections on personal factors associated with Aboriginal and Torres Strait Islander populations did include input from Aboriginal and Torres Strait Islander people. The final 
Table 1 Best Practice Statement contributions matrix

\begin{tabular}{|c|c|c|c|c|c|c|}
\hline Member & $\begin{array}{l}\text { Process (core } \\
\text { group, expert panel, } \\
\text { additional expert) }\end{array}$ & $\begin{array}{l}\text { Professional role } \\
\text { (research, clinical, } \\
\text { management, policy) }\end{array}$ & $\begin{array}{l}\text { ICF (Impairment, activity/ } \\
\text { participation, environment, } \\
\text { personal factors) }\end{array}$ & $\begin{array}{l}\text { Continuum of care } \\
\text { (acute, inpatient, } \\
\text { community) }\end{array}$ & $\begin{array}{l}\text { Geographical location } \\
\text { by state (metropolitan } \\
\text { unless stated) }\end{array}$ & $\begin{array}{l}\text { Principle area } \\
\text { of expertise } \\
\text { (domains 1-8) }\end{array}$ \\
\hline $\begin{array}{l}\text { Professor Linda } \\
\text { Worrall }\end{array}$ & $\begin{array}{l}\text { Core group } \\
\text { Expert panel }\end{array}$ & Research & Activity, participation, environment & $\begin{array}{l}\text { Acute, inpatient, } \\
\text { community }\end{array}$ & Queensland & $1-6$ \\
\hline $\begin{array}{l}\text { Associate } \\
\text { Professor } \\
\text { Miranda Rose }\end{array}$ & $\begin{array}{l}\text { Core group } \\
\text { Expert panel } \\
\text { additional expert }\end{array}$ & Research & Impairment, activity, participation & Acute, community & Victoria & $1-6$ \\
\hline $\begin{array}{l}\text { Professor } \\
\text { Leanne Togher }\end{array}$ & $\begin{array}{l}\text { Core group } \\
\text { Expert panel }\end{array}$ & Research & Activity, participation, environment & Inpatient, community & New South Wales & $1-6$ \\
\hline $\begin{array}{l}\text { Professor } \\
\text { Lyndsey Nickels }\end{array}$ & Expert panel & Research & Impairment & Inpatient, community & New South Wales & $4-5$ \\
\hline $\begin{array}{l}\text { Dr Erin } \\
\text { Godecke }\end{array}$ & $\begin{array}{l}\text { Expert panel } \\
\text { additional expert }\end{array}$ & Research, clinical & Impairment, environment & Acute & Western Australia & $2,4-6$ \\
\hline $\begin{array}{l}\text { Associate } \\
\text { Professor } \\
\text { Deborah Hersh }\end{array}$ & $\begin{array}{l}\text { Expert panel } \\
\text { additional expert }\end{array}$ & Research & Participation, personal factors & Acute, community & Western Australia & 5,7 \\
\hline Ms Kim Clarke & Expert panel & Clinical, managerial & $\begin{array}{l}\text { Impairment, activity, participation, } \\
\text { personal factors }\end{array}$ & $\begin{array}{l}\text { Acute, inpatient, } \\
\text { community }\end{array}$ & South Australia (rural) & $1-8$ \\
\hline Ms Sue Lamont & Expert panel & Clinical, managerial & $\begin{array}{l}\text { Impairment, activity, participation, } \\
\text { environment and personal factors }\end{array}$ & $\begin{array}{l}\text { Acute, inpatient, } \\
\text { community }\end{array}$ & Victoria & $1-8$ \\
\hline $\begin{array}{l}\text { Ms Claire } \\
\text { O'Connor }\end{array}$ & Expert panel & Managerial, policy & Environment (systems) & $\begin{array}{l}\text { Acute, inpatient, } \\
\text { community }\end{array}$ & New South Wales & $1-8$ \\
\hline Dr Emma Power & $\begin{array}{l}\text { Expert panel- } \\
\text { facilitator }\end{array}$ & Research & NA & NA & New South Wales & NA \\
\hline Ms Emma & Core group & Research & NA & NA & Queensland & NA \\
\hline Thomas & $\begin{array}{l}\text { Expert panel—project } \\
\text { manager and scribe }\end{array}$ & & & & & \\
\hline $\begin{array}{l}\text { Dr Robyn } \\
\text { O'Halloran }\end{array}$ & Additional expert & Research, clinical & Environment & Acute, inpatient & Victoria & 6 \\
\hline $\begin{array}{l}\text { Professor Beth } \\
\text { Armstrong }\end{array}$ & Additional expert & Research & $\begin{array}{l}\text { Impairment, activity/participation, } \\
\text { personal factors aboriginal and } \\
\text { torres strait Islander populations }\end{array}$ & $\begin{array}{l}\text { Acute, inpatient, } \\
\text { Community }\end{array}$ & Western Australia & 7 \\
\hline Dr Zaneta Mok & Additional expert & Research & $\begin{array}{l}\text { Personal factors (CALD } \\
\text { populations) }\end{array}$ & Community & Victoria & 7 \\
\hline $\begin{array}{l}\text { Dr Karen } \\
\text { Brewer }\end{array}$ & Additional expert & Research & $\begin{array}{l}\text { Personal factors (aboriginal and } \\
\text { torres strait Islander people/Maori } \\
\text { populations) }\end{array}$ & $\begin{array}{l}\text { Acute, inpatient, } \\
\text { Community }\end{array}$ & New Zealand & 7 \\
\hline
\end{tabular}


Table 2 Example of the format of the statements for use in the validation procedure

\begin{tabular}{lll}
\hline Statement and rationale & Reference & $\begin{array}{l}\text { Level of NHMRC } \\
\text { evidence }\end{array}$ \\
\hline 5.7 Group therapy and conversation groups can be used for people with aphasia & Lanyon, Rose and & I \\
and should be available in the longer term for those with persisting aphasia. & Worrall $^{36}$ & \\
Rationale: Community and outpatient group participation can improve specific & \\
linguistic processes for people with aphasia. There is also evidence that group & \\
participation can benefit social networks and community access. However, there & \\
is currently insufficient evidence to demonstrate that people with aphasia have & \\
improvement in functional communication as a consequence of group & \\
participation & \\
\hline NHMRC, National Health and Medical Research Council.
\end{tabular}

document contained 74 BPS across the eight areas of care. Each final statement was accompanied by its corresponding level of evidence, source study reference and a rationale (see table 2 for an example).

\section{Validation of statements}

Our procedure followed the RAM guidelines ${ }^{28}$ consisting of a two-round modified Delphi method with an added face-to-face component that allows members to discuss their judgements between rating rounds. ${ }^{28}$ Basger et $a l^{31}$ highlighted the importance of the face-to-face component in allowing discussion to resolve misinterpretation, introduce new evidence and improve clarity. Experiences with the RAM and other group processes indicate that the potential for bias in the face-to-face group can be largely controlled by effective group leadership. ${ }^{28}$ Therefore, the panel facilitator was experienced in moderating group discussions and an experienced RAM facilitator provided additional training and advice to the Aphasia RAM facilitator.

\section{Participants-national expert panel}

The panel comprised of nine qualified, Australian speech pathologists $^{\mathrm{i}}$ with significant expertise in post-stroke aphasia rehabilitation (see table 1). We used the standard sample size recommended in the RAM manual $(n=9)$. This number of panellists was considered sufficient to permit a diverse sample and also provide an opportunity for panel members to be involved in the group discussion in Round $2{ }^{28}$ We used purposive sampling across a range of factors (see table 1) to maximise the opportunity for a diverse range of perspectives and expertise. Factors included varied professional roles and skill sets (ie, research, clinical, managerial and policy-based), geographical region (ie, different states/cities as well as rural and metropolitan areas), expertise across a range of rehabilitation settings (ie, acute, inpatient and community) and the International Classification of Functioning, Disability and Health (ICF) $)^{37}$ (ie, Impairment, Activity/Participation,

${ }^{\mathrm{i}}$ Due to the Australian context of the study, we use the term 'speech pathologist', which is synonymous with the term 'speech and language therapist' adopted in the United Kingdom.
Environmental Factors and Personal Factors). The initial nine members who were invited to take part in the RAM process all agreed and participated in both rating rounds.

\section{RAM rating round 1}

The first round involved individual ratings of statements that were distributed to panel members through email. The facilitator (EP) contacted each panellist to explain the RAM procedure and clarify any questions. The panellists were then emailed: a copy of the BPS complete with a summary of the evidence and NHMRC level of evidence ${ }^{35}$ instructions on how to perform the ratings according to the definition of appropriateness provided in the RAM manual $;^{28}$ a score sheet; a list of abbreviations and definitions; and an EndNote library complete with full texts of every reference. The facilitator's contact details were provided so that any queries in regards to how to perform the ratings could be answered. The panellists rated the 'appropriateness' of each statement on a scale of one to nine, with nine being the most 'appropriate'. ${ }^{28}$ They were also able to record comments to explain their scores. Panel members retained copies of their comments to aid in discussion for the second round of rating. Completed score-sheets with any comments were then returned by email to the project manager. The scores and comments were recorded onto a central database file. The panel facilitator checked the accuracy of the transfer of all entries and comments.

\section{Analysis}

Following the RAM guidelines, ${ }^{28}$ median scores were calculated for each statement and the number of panellists rating outside the median tertile was recorded. Statements were classified and agreed to as valid based on the median rating of appropriateness and the degree of panel agreement (dispersion). Statements with a median panel score in the top tertile (7-9) without disagreement were classified as 'appropriate', median ratings in the bottom tertile (1-3) without disagreement were classified as 'inappropriate', and median scores between 4 and 6 or any median with disagreement was classified as neither appropriate or appropriate but as 
Table 3 Best practice statements (BPS) for each area of care $(n=74)$ presented with median panel score and number of panellists that scored outside the median tertile BPS practice statements (BPS) for each area of care $(n=74)$ presented with median panel score and number of panellists that score

number ROUND 1 Aphasia Rehabilitation BPS 2014

Median Number of outside RECEIVING THE RIGHT REFERRALS

\section{Community awareness of aphasia}

$1.1 \quad$ Speech pathologists should endeavour to raise community awareness of aphasia

Speech pathologists should highlight that aphasia is a symptom of stroke

The speech pathologist should ensure that appropriate stroke information is provided to his/her client (eg, the risk of

secondary stroke, preventative techniques, the identification of stroke using the FAST mnemonic, recognising that stroke is
a medical emergency)

\section{Communication training of health professionals}

$1.4 \quad$ Speech pathologists should provide communication training to health professionals involved in the care of people with aphasia (including where possible: emergency response staff, stroke unit staff and rehabilitation staff) and provide strategies for enhancing communication

\section{Referral process}

Person with suspected stroke (and possible aphasia) should be transferred directly to a hospital with an acute stroke unit and admitted to the acute stroke unit

All persons with suspected stroke (and possible aphasia) should be referred to a speech pathologist

If blanket referrals are not feasible, patients should be screened for communication deficits using a screening tool that is valid and reliable

\section{OPTIMISING INITIAL CONTACT}

Initial assessment

2.1 Those patients with suspected aphasia should receive assessment by a speech pathologist to determine the presence and severity of aphasia

2.2 Those patients with suspected aphasia should receive assessment by a speech pathologist to determine the patient's ability to communicate their healthcare needs in hospital

\section{Initial prognosis}

2.3 Speech pathologists should consider the initial severity of the stroke and aphasia when predicting a patient's language recovery

\section{Initial management}

$2.4 \quad$ Speech pathologists should identify the patient and family's needs and readiness for information and education, training, psychosocial support and health and social services

2.5 People with aphasia and their family/carers should be offered information about stroke and aphasia tailored to meet their needs using relevant language and communication formats

2.6 Speech pathologists should offer to teach the family/ carers of patients with aphasia strategies that may enhance communication with each other

2.7 Speech pathologists should provide hospital staff with specific communication strategies that are tailored to enhance communication with each patient with aphasia

3 SETTING GOALS AND MEASURING OUTCOMES

\section{Goal setting}

3.1 Goal setting should be a dynamic process that is reviewed throughout the continuum of care in order to reflect client and family context and wishes

3.2 Therapists should explain the goal setting process (and the potential benefits) to the client and their family in an accessible way and assist in the identification of goal areas prior to formal assessment 

client/family with consideration of results from formal and informal assessment

Systems should be established to ensure involvement of people with aphasia and their family as part of the multidisciplinary team (ie, MDT goal setting at the client's bedside)

3.5 The 'SMARTER' framework* could be used to help ensure that goal setting is truly collaborative and client-centred

\section{Measuring outcomes}

Outcome measures should be relevant, meaningful, and important to stakeholders

Outcome measures should be suitable (to the construct being measured) and psychometrically robust (reliable, valid and sensitive)

Outcome data should be reported in a full and unbiased manner to stakeholders

\section{ASSESSING}

The assessment process should be iterative and dynamic

Assessment should be therapeutic

All domains of functioning and disability International Classification of Functioning, Disability and Health (ICF) should be considered for assessment

All stakeholders (person with aphasia, family member, therapist) should be invited to contribute to the assessment

All assessment results should be documented and accessible to clients and their families

\section{PROVIDING INTERVENTION}

People with aphasia should be offered therapy to gain benefits in receptive and expressive language, and communication

5.1
in everyday environments

Therapy intensity and delivery can be enhanced by computer-based treatments. People with chronic aphasia ( $>6$ months post-stroke) can benefit from computer delivered language therapy

People with chronic aphasia (>6 months post-stroke onset) can benefit from therapy and can be offered a range of efficacious intervention such as the use of computer-based treatments, constraint-induced therapy, group language therapies and training conversation/communication partners

Intervention can include constraint-induced language therapy

Treatment to improve communication activities and/or participation should include Supported Conversation techniques for

\section{7}

communication partners of the person with aphasia

Treatment to improve word retrieval can include discourse treatment

Group therapy and conversation groups can be used for people with aphasia and should be available in the longer term for those with persisting aphasia

Persons with aphasia should have access to intensive SLT if they can tolerate it.

Intervention can include

- treatment of aspects of language (including phonological and semantic deficits, sentence-level processing, reading and writing) following models derived from cognitive neuropsychology

- therapy for word-retrieval and production disorders

Gesture can be incorporated in SLT to improve communication

People with aphasia can benefit from high technology communication devices and computer software

The impact of aphasia on functional activities, participation and quality of life including the impact on relationships, vocation and leisure, should be addressed as appropriate from post-onset and over time for those chronically affected 
6.1 Communication partner training should be provided to improve the communication activities and/or participation of frequent

communication partners of the person with aphasia

6.2 People with aphasia should be offered a choice of aphasia friendly formats when given written information

To create communicatively accessible environments for people with aphasia it is recommended consideration be given to

- Establishing an advisory group that includes multiple perspectives and expertise

- Involving people with aphasia at every step

- Drawing on relevant legislation, organisational values and research evidence and implementation science to motivate for change

\section{ENHANCING PERSONAL FACTORS}

\section{Mood}

Clinicians should ensure that both the patients and their family are able to monitor their mood and know where to seek help 8 if their emotional state declines

Clinicians should facilitate connections with appropriate social supports where possible

\section{Culturally and linguistically diverse populations (CALD): general}

Speech pathologists should consider both cultural and linguistic factors of the person/family with aphasia that may have an impact on service delivery

Where the speech pathologist is not proficient in a language of the person with aphasia, a trained and qualified interpreter knowledgeable with the specific requirements for speech pathology, should be used

\section{Assessment}

Where a patient reports having used more than one language pre-morbidly, comprehensive information about the patient's language history should be obtained

Where possible, assessments should be used that are appropriate to the languages/dialects and cultural backgrounds of each client

\section{Intervention}

Where possible, treatment should be provided in all relevant languages (and the relevant modalities), and should not systematically exclude a language

7.8 Language behaviours unique to the bilingual such as translation, language mixing and switching should be considered in both assessment and intervention planning

Working with people from Aboriginal and Torres Strait Islander backgrounds

7.9 Speech pathologists should obtain training in cross-cultural competence with particular reference to Aboriginal and Torres Strait Islander cultures

7.10 Speech pathologists should investigate local protocols that guide working with Aboriginal and Torres Strait Islander people and communities

7.11 Speech pathologists should routinely check Aboriginal and Torres Strait Islander status in medical file and with the clients themselves

7.12 Speech pathologists should involve an Aboriginal Liaison Officer (ALO) where possible to advise on cultural issues and liaise with client and family

7.13 Speech pathologists should access appropriate interpreter services if needed. Where these are not available in the geographical area where the hospital/rehabilitation service is located, services should be sought via telephone or other media 
7.14 Speech pathologists should use a variety of means. For example pictures, story-telling, information conveyed on iPads to explain Speech Pathology terms in order to help the client and their family understand the Speech Pathology context. The information should be provided in a way that is relevant and culturally appropriate to an Aboriginal/Torres Strait Islander context that is, pictures of familiar contexts, familiar terms to equate with professional jargon

Speech pathologists should include some yarning time within the assessment process that is, time talking about personal backgrounds (both therapist and client)

7.16 Speech pathologists should talk with the client and their family about the roles the client has in the family and community

7.17 Speech pathologists should take a holistic approach to assessment and management that is aligned to an Aboriginal and Torres Strait Islander worldview. This may include:

- Working closely with family (including family members non-Aboriginal and Torres Strait Islander Australians would call 'extended family')

- Working jointly with other allied health colleagues (joint sessions etc)

- Making pre-discharge links with the client's local Aboriginal Medical Service if they are associated with one

- Being flexible with therapy context eg, include home visits

- Making opportunities for the client to participate in yarning and social activity if they would like it

Speech pathologists should endeavour to tailor assessments to be culturally appropriate

7.18 specific social services

7.19

Speech pathologists should have mentors and develop reflective practice skills so that they learn from each experience with

an Aboriginal or Torres Strait Islander client and improve the service they provide with each new client

8 PLANNING FOR TRANSITIONS

8.1 Planning for the next phase (transfer to rehabilitation, home, aged care) should be initiated as early as possible

Where a person with aphasia is due for discharge from a hospital ward, or inpatient facility, a speech pathologist part of the multidisciplinary discharge planning team and adopt an advocacy role to ensure optimal care. Multiple opportunities should be made available, from early on, for both the patient and carer to discuss their available options as well as any fears or concerns shared with the receiving healthcare providers should be provided to the patient, family and carers. This should be in an aphasia-friendly format. Additional support may be required for those whose first language is not English

- The clinician can consider providing solutions and training to the communication requirements of returning safely home (eg, getting help in an emergency, safely answering the door)

- Ensure that communication problems do not prevent the patient from getting out of the home. Public transport or return to driving training may need to accommodate the aphasia carefully linked in with ongoing supports and appropriately prepared for the transition

The clinician should endeavour to connect the person with aphasia and their family with other people with aphasia, aphasia groups or support organisations while they are still in hospital, particularly if they live alone 


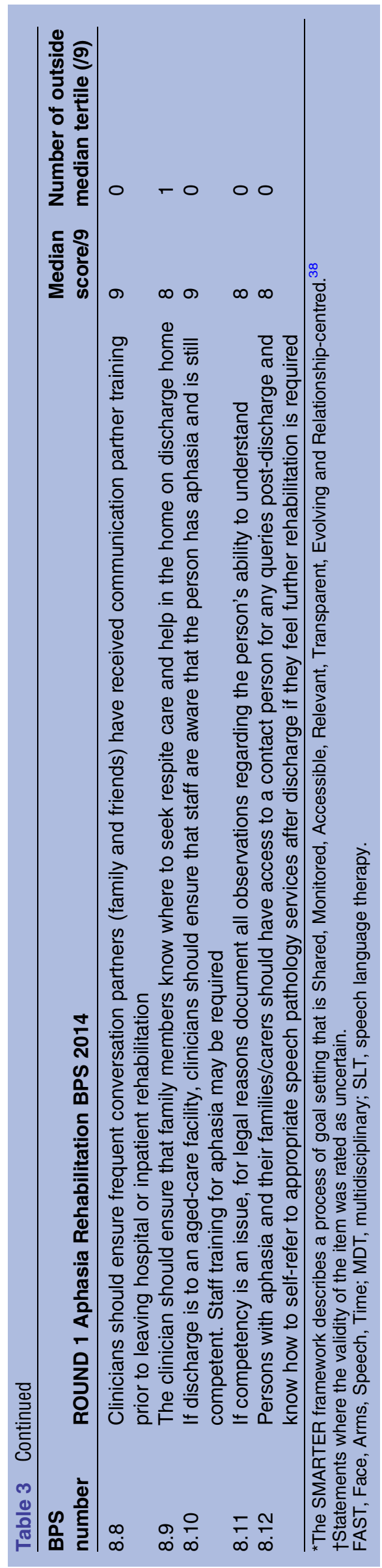

'uncertain'. Using the guidelines for a nine member panel, ${ }^{28}$ agreement was indicated when no more than two panellists rated the statement outside the three point region (1-3; 4-6; 7-9) containing the median score. Disagreement was indicated when at least three panellists rated the statement in the lower third region (1-3) and at least three panellists rated it in the top third region (7-9). A simple content analysis was performed by the facilitator and project manager (EP, ET) on the comments to provide a preliminary understanding of the nature of any issues panel members had with the statements. There was no further analysis of the comments as their primary purpose was to aid in the discussion of items in the face-to-face round (see below).

\section{RAM rating round 2}

All nine panel members attended the second round face-to-face meeting which occurred in Sydney in November 2013, 2 weeks after all panel members had completed their first round ratings. All discussions were audiotaped with the consent of the panellists. Two members were unable to attend for the entire day and were provided with an audio recording for the sections they missed. During this round, each panel member was provided with a score-sheet containing both their original rating for each item and the panel's median score for each statement. Panellists discussed the wording of the BPS and any other issues associated with each BPS, such as the nature of the evidence. Panellists did not explicitly discuss their scores with each other and once the discussion was completed, panellists then re-rated each statement anonymously without discussion. The same analysis procedure as before was applied to the second round rating. To be classified as 'appropriate' and retained for the final best practice statement document, the statements needed to achieve a median rating between 7-9 and have no more than two panellists rate below 7 .

\section{RESULTS}

\section{Round 1}

Seventy-four BPS were rated across the eight areas of care developed by the CoP (see table 3). At the end of Round 1,71 of the 74 statements were rated as appropriate (median rating between 7 and 9 with no disagreement) and no statements were rated as inappropriate. Three statements were rated as uncertain with one with a median rating of 6 and disagreement (table 3: BPS 5.4 ), and the other two statements had median ratings in the appropriate range (7-9), but more than two panellists scored below 7 (table 3: BPS 5.6, 7.7). Of the 71 'appropriate' statements, $34(48 \%)$ had one or two ratings below 7 , indicating that some minor discrepancies between panellists existed. Nearly all raters provided comments that centred mainly on: (1) the degree to which the statement was consistent with speech 
pathologists' scope of practice, (2) statement wording, and (3) the source evidence.

\section{Round 2}

As no statements were rated as inappropriate in Round 1, all 74 statements were then retained and rated again in the second round face-to-face meeting. Owing to time constraints, the ratings of two of the eight sections had to be completed in a teleconference after the face-to-face meeting. During the meeting, 16 statements were added by consensus through splitting existing items or adding new statements. This splitting and addition occurred mostly in the Intervention section (Section 5) in Round 2 where the panel expressed dislike of the format of the section and key missing statements. Their feedback was documented; however, due to time constraints, rating of the section was postponed to the teleconference. Between Round 2 and the teleconference, the section was reformatted and new additions made based on panel feedback with updated references, where required. Seven statements were deleted leaving 83 statements. Statements were deleted because they were considered too broad in nature (eg, table 3: BPS 2.4) or were replaced by other statements or there were questions whether the statement adequately reflected the role and scope of the speech pathologist (eg, table 3: BPS 8.9). Most of the 83 statements were edited during the face-to-face meeting to ensure consistency of wording and terminology. All statements in Round 2 scored a median appropriateness score of 9 with the exception of two statements that scored 8. Agreement was reached for 82 of the final 83 statements, and a statement on outcome measures (table 3: BPS 3.6) was then excluded from the final version as three panel members scored outside the median range (7-9). The final 82 statements are presented in the online supplementary materials. The comprehensive version of the statements, including detailed rationales, references and level of evidence, can be found in the online supplementary materials or at http://www.aphasiapathway.com.au.

The final statements were based on a combination of evidence and expert opinion. In summary, 35 (42\%) of the 82 statements were supported by quantitative evidence and 23 of those 35 statements were supported by the highest level of evidence (level I ${ }^{35}$ ). Sixteen (20\%) of the statements were supported by qualitative evidence and $31(38 \%)$ were supported by expert opinion. Eleven of these 31 were in the section on Enhancing Personal Factors that included working with people from culturally and linguistically diverse, and Aboriginal and Torres Strait Islander backgrounds.

\section{DISCUSSION}

Consensus has been reached on 82 Aphasia Rehabilitation Best Practice Statements across eight domains of care using the RAM quality indication development and validation process. As the dissemination of guidelines alone does not necessarily result in implementation, ${ }^{39}$ these statements have been integrated into a dynamic and accessible online implementation resource, the Australian Aphasia Rehabilitation Pathway (AARP: http://www. aphasiapathway.com.au). Each statement is accompanied by clinical resources to assist implementation efforts. In producing the BPS and AARP, we have responded to evidence from clinicians ${ }^{922}$ and consumers ${ }^{14}$ that there is a need for more detailed recommendations and a clearer pathway of care for aphasia.

The 82 statements over eight domains of care represent a considerable expansion of the number of aphasia-related statements contained in current stroke guidelines. While there were additions in all domains, one of the principal areas for an increase in recommendations was in the Personal Factors domain, in particular, for culturally and linguistically diverse populations (see online supplementary materials; 11 statements, BPS 7.3-7.13) and Aboriginal and Torres Strait Islander populations (9 statements, BPS 7.14-7.22). These populations pose particular challenges for speech pathologists when providing appropriate care to people with aphasia. The Australian stroke guidelines do refer very briefly to consideration of cultural and linguistic diversity in the assessment of people with aphasia, but further guidance in this area for indigenous peoples in particular was lacking. An additional expert panel was engaged to provide more specific information to these statements. Additionally, we referenced the New Zealand stroke guidelines ${ }^{40}$ which include specific statements tailored to the Maori population. Inclusion of these statements represents an important step towards understanding, respecting and representing Indigenous world-views, encouraging culturally appropriate working practices and valuing cultural diversity.

Another feature of the statements is that while $28 \%$ of the statements were rated as Level I evidence, ${ }^{35}$ a large proportion $(58 \%)$ were supported by either qualitative evidence $(20 \%)$ or expert opinion (38\%), particularly in the Personal Factors section. This finding may be expected for a developing area of research. ${ }^{41}$ For example, until recently very few studies had been published on aphasia and Aboriginal and Torres Strait Islander populations and the evidence in the BPS represents the early phases of research in this area. ${ }^{4-44}$ Additionally, one advantage of the process of guideline development is that it can highlight the evidence gaps more clearly and focus researchers on areas of practice where more high quality evidence is required. Through the development of the BPS, the CCRE in Aphasia Rehabilitation has been able to identify where the gaps in evidence lay, and has focused research efforts on these gaps in combination with priority areas identified by clinicians, ${ }^{9}$ consumers ${ }^{14}$ and international clinical and research organisations. ${ }^{45}$ Therefore, in addition to the creation and validation of best practice statements, the RAM process has focused research agendas on areas of need. ${ }^{39}$ 
Owing to the above factors associated with the quality of the current aphasia rehabilitation evidence, the RAM method was ideally suited for the validation of BPS through a combination of research evidence and expert opinion. ${ }^{28}$ One of the advantages of the RAM process is that it contains a face-to-face discussion round. ${ }^{28} 31$ This round provided the panel with the opportunity to discuss their opinions and assumptions underlying their ratings and the source evidence in addition to modification of the wording of statements. There were very high levels of agreement in both Rounds 1 (see above) and 2 (82/83 agree appropriate, and median rating of 9 for $80 / 82$ final statements).

\section{Strengths and limitations}

We have utilised a method of validation recommended for areas of practice where there is a lack of high quality evidence across domains of care. ${ }^{22}$ Owing to the vulnerability of people with aphasia to poor long-term psychosocial outcomes, ${ }^{10-13}$ it is critical to have validated BPS available for clinicians that incorporate research evidence and expert opinion where this research is lacking in order to provide a foundation for quality and consistent care provision. In the development process, we engaged a range of stakeholders through our CoP to develop the AARP domains and a diverse panel with expertise in research, clinical and managerial practice as well as policy to validate the BPS. However, it is possible that we did not identify all articles in our review and it may not have been exhaustive given the continuing development of the published evidence. Despite this, we have created a strong foundation for the continued revision and updating of the BPS in the future. Additionally, the judgements made by a single panel of speech pathologists may not be representative of all clinicians, researchers and policymakers. Two panel members were unable to attend the whole face-to-face meeting and they provided their ratings after listening to the recorded discussion. While their input was considered separately, their absence for those sections may have affected the nature of the discussion. We also did not return the final, validated BPS to the broader CoP to gain wider national consensus.

The majority of the BPS data should be internationally applicable. While there are some promising new guidelines available internationally, such as the Canadian Stroke Best Practice Stroke Recommendations which include nine recommendations specific to aphasia management, there remains a paucity of rigorously reported BPS guidelines for aphasia. ${ }^{15}$ Prior to publication of the BPS, the most robust clinical guidelines to address stroke management included the Australian Clinical Guidelines for Stroke Management ${ }^{16}$ and the New Zealand Clinical Guidelines for Stroke Management; ${ }^{40}$ however, these were not developed using the ICF framework nor do they focus on aphasia management across the continuum of care ${ }^{15}$ One strength of the BPS is the inclusion of a comprehensive section on Personal
Factors relating to culturally and linguistically diverse and indigenous populations. While this inclusion might encourage the international community to address such Personal Factors, the BPS may require adaptation for other regions and nations, especially for those sections that have been heavily contextualised for Australian practice and society.

\section{Future directions}

The BPS are suitable for use as an audit tool in clinical settings. This process will identify particular statements where there is either consistency or variation in practice, and those that have variation can be targeted for either broader translation initiatives involving evidence-based implementation strategies ${ }^{46}$ or local quality improvement projects. ${ }^{47}$ The future production of a consumer friendly version that incorporates 'aphasia friendly' formatting and language ${ }^{48}$ will potentially enhance the active participation of people with aphasia and their families in the rehabilitation process, and provide them with information about their care at each phase of their journey. ${ }^{46}$ Further consultation with other health professionals involved in the care of people with aphasia is also warranted. As new evidence emerges, the BPS will be updated to reflect the current state of the knowledge in this field. Additionally, we will continue to work with our collaborators to ensure the BPS influence future iterations of other stroke and aphasia guidelines, nationally and internationally.

\section{CONCLUSION}

We have developed evidence-based and expert-endorsed BPS for aphasia rehabilitation. These statements form a crucial part of the Australian Aphasia Rehabilitation Pathway (http://www.aphasiapathway.com.au). The aphasia BPS represent a critical foundation step for a national implementation effort in stroke care/rehabilitation.

\section{Author affiliations}

${ }^{1}$ Speech Pathology, Faculty of Health Sciences, The University of Sydney, Lidcombe, New South Wales, Australia

${ }^{2}$ Centre for Clinical Research Excellence in Aphasia Rehabilitation

${ }^{3}$ School of Health and Rehabilitation Sciences, the University of Queensland, St Lucia, Queensland, Australia

${ }^{4}$ Department of Human Communication Sciences, School of Allied Health, La Trobe University, Bundoora, Victoria, Australia

${ }^{5}$ Department of Cognitive Science, ARC Centre of Excellence in Cognition and its Disorders, Macquarie University, Sydney, New South Wales, Australia

${ }^{6}$ Speech Pathology, School of Psychology and Social Science, Edith Cowan University, Perth, Western Australia, Australia

${ }^{7}$ Department of Speech Pathology, Monash Health, Melbourne, Victoria, Australia

${ }^{8}$ NSW Agency for Clinical Innovation, Chatswood, New South Wales, Australia ${ }^{9}$ Speech Pathology, Country Health SA Local Health Network, Strathalbyn, South Australia, Australia

\section{Twitter Follow Emma Power at @dr_epower}

Acknowledgements For their contributions to the development of the best practice statements, the team would like to acknowledge: Dr Zaneta Mok, Dr Anne J Hill, Ms Alexia Rohde, Ms Sarah Wallace, Dr Karen Brewer, 
Dr Denise 0'Connor and the Missing Voices project team (Professor Beth Armstrong, Associate Professor DH, Associate Professor Judith Katzenellenbogen, Associate Professor Julianne Coffin, Professor Sandra Thompson, Dr Natalie Ciccone, Professor Colleen Hayward, Deborah Woods, Professor Leon Flicker and Ms Meaghan McAllister, Edith Cowan University); the Aphasia Rehabilitation Community of Practice, including the Australian Aphasia Association, National Stroke Foundation, and the clinicians who attended the CoP meetings; the CCRE in Aphasia Rehabilitation Chief and Associate investigators, postdoctoral research fellows, higher degree and honours research students. The authors would also like to acknowledge Dr Benjamin Basger for his generous consultation on the RAND/UCLA procedures.

Contributors EP, ET, LW, MR, and LT contributed to the project conceptualisation, design, data collection, analysis and editing of final manuscript. EP and ET drafted the manuscript. EP facilitated the RAM process. The remaining authors made substantial contribution to data collection, interpretation and analysis through either the development of the best practice statements and /or contributions of the RAM panel. All authors have contributed to the critical editing of the paper. All authors take responsibility for the accuracy and integrity of the data, and have given approval for the final version to be published.

Funding This study was funded by an Australian National Health and Medical Research Council Centre for Clinical Research Excellence grant (569935).

Competing interests All authors have completed the ICMJE uniform disclosure form at http://www.icmje.org/coi_disclosure.pdf and declare: EP, ET, LW, MR, LT, LN, RO, and EG had financial support from the Australian National Health and Medical Research Council Centre for Clinical Research Excellence grant (569935). Additionally, financial support was provided to MR and LN (Australian Research Council Future Fellowships), LT (Australian National Health and Medical Research Council Senior Research Fellowship). $\mathrm{DH}, \mathrm{SL}, \mathrm{CO}$ and KC had no financial support for this work; none of the authors had financial relationships with any organisations that might have an interest in the submitted work in the previous 3 years; none of the authors had other relationships or activities that could appear to have influenced the submitted work

Ethics approval University of Queensland Human Ethics Committee (approval number 2009001850).

Provenance and peer review Not commissioned; externally peer reviewed.

Data sharing statement No additional data are available.

Open Access This is an Open Access article distributed in accordance with the Creative Commons Attribution Non Commercial (CC BY-NC 4.0) license, which permits others to distribute, remix, adapt, build upon this work noncommercially, and license their derivative works on different terms, provided the original work is properly cited and the use is non-commercial. See: http:// creativecommons.org/licenses/by-nc/4.0/

\section{REFERENCES}

1. Benson DF, Ardila A. Aphasia: a clinical perspective. New York: Oxford University Press, 1996

2. Engelter ST, Gostynski M, Papa A, et al. Epidemiology of aphasia attributable to first ischemic stroke: incidence, severity, fluency, etiology, and thrombolysis. Stroke 2006;37:1379-84.

3. Dickey L, Kagan A, Lindsay $P$, et al. Incidence and profile of inpatient stroke-induced aphasia in Ontario, Canada. Arch Phy Med Rehab 2010;91:196-201.

4. Enderby $P$, Davies P. Communication disorders: planning a service to meet the needs. Br J Disord Commun 1989;24:301-31.

5. Ellis $\mathrm{C}$, Simpson AN, Bonilha $\mathrm{H}$, et al. The one-year attributable cost of poststroke aphasia. Stroke 2012:43:1429-31.

6. Hemsley B, Werninck M, Worrall I. "That really shouldn't have happened": people with aphasia and their spouses narrate adverse events in hospital. Aphasiol 2013b;27:706-22.

7. Bartlett $\mathrm{G}$, Blais R, Tamblyn R, et al. Impact of patient communication problems on the range of preventable adverse events in acute care settings. CMAJ 2008;178:1555-62.
8. Foster A, O'Halloran R, Rose M, et al. "Communication is taking a back seat": speech pathologists' perceptions of aphasia management in acute hospital settings. Aphasiology early online, 2015. doi:10.1080/02687038.2014.985185

9. Rose M, Ferguson A, Power E, et al. Aphasia rehabilitation in Australia: current practices, challenges and future directions. Int $J$ Speech Lang Pathol 2014;16:169-80.

10. Cruice M, Worrall L, Hickson L. Quantifying aphasic people's social lives in the context of non-aphasic peers. Aphasiology 2006;20:1210-25.

11. Grawburg M, Howe T, Worrall L. et al Describing the impact of aphasia on close family members using the ICF framework. Disabil Rehabi 2014;36:1184-95.

12. Hilari K, Byng S. Health-related quality of life in people with severe aphasia. Int J Lang Commun Disord 2009;44:193-205.

13. Vickers CP. Social networks after the onset of aphasia: the impact of aphasia group attendance. Aphasiology 2010;24:902-13.

14. Worrall $L$, Sherratt $S$, Rogers $P$, et al. What people with aphasia want: their goals according to the ICF. Aphasiology 2011;25:309-22.

15. Rohde A, Worrall L, Le Dorze G. Systematic review of the quality of clinical guidelines for aphasia in stroke management. J Eval Clin Pract 2013;19:994-1003.

16. National Stroke Foundation. Clinical guidelines of stroke management 2010. Melbourne, Australia, 2010. http:// strokefoundation.com.au/site/media/clinical_guidelines_stroke_ managment_2010_interactive.pdf (accessed 23 Apr 2011).

17. Hubbard IJ, Harris D, Kilkenny MF, et al. Adherence to clinical guidelines improves patient outcomes in Australian audit of stroke rehabilitation practice. Arch Phys Med Rehabil 2012;93:965-71.

18. National Stroke Foundation. National Stroke Audit-Acute Services Organisational Survey Report 2013. Melbourne, Australia, 2013. http://strokefoundation.com.au/site/media/NSF_Audit_OrgReport_ 2013_web2.pdf (accessed 17 Oct 2013).

19. Godecke E, Hird K, Lalor EE, et al. Very early poststroke aphasia therapy: a pilot randomized controlled efficacy trial. Int J Stroke 2012;7:635-44.

20. Brady MC, Kelly H, Godwin J, et al. Speech and language therapy for aphasia following stroke. Cochrane Database Syst Rev 2012;5: CD000425. http://onlinelibrary.wiley.com/doi/10.1002/14651858. CD000425.pub3/abstract (accessed 5 Mar 2013).

21. Canadian Stroke Network. The quality of stroke care. Canada, 2011. http://canadianstrokenetwork.ca/en/wp-content/uploads/2014/08/ QoSC-EN.pdf

22. Hadley KA, Power E, O'Halloran R. The barriers and facilitators that influence speech pathologists' use of stroke clinical practice guidelines-a national descriptive study. BMC Health Serv Res 2014;14:110. http://www.biomedcentral.com/1472-6963/14/110 (accessed 6 Mar 2014)

23. Howe T, Davidson B, Worrall L, et al. 'You needed to rehab... families as well': family members' own goals for aphasia rehabilitation. Int J Lang Commun Disord 2012;47:511-21.

24. Thomas E, Power E, Worrall L, et al. A national approach to improving aphasia services: application of a knowledge transfer and exchange framework. J Clin Pract Speech Lang Pathol 2014;16:30-6.

25. Kwan J, Hand P, Dennis M, et al. Effects of introducing an integrated care pathway in an acute stroke unit. Age Ageing 2004;33:362-7.

26. Kwan J, Sandercock P. In-hospital care pathways for stroke. Cochrane Database Syst Rev 2004;(4):CD002924. http://onlinelibrary.wiley.com/ store/10.1002/14651858.CD002924.pub2/asset/CD002924.pdf? $\mathrm{v}=1 \& \mathrm{t}=\mathrm{i} 89 \mathrm{~m} 852 \mathrm{a} \& \mathrm{~s}=25 \mathrm{a} 430 \mathrm{~d} 39 \mathrm{e} 848 \mathrm{e} 5 \mathrm{a} 497 \mathrm{~b} 8 \mathrm{~b} 9315 \mathrm{f5} 19 \mathrm{af83d} 4 \mathrm{ea} 2 \mathrm{~d}$ (accessed 23 Jun 2013).

27. National Health Service Quality Improvement Scotland. Best practice statement: prevention and management of ulcers. Edinburgh, UK. 2009. http://www.healthcareimprovementscotland.org/previous resources/best_practice_statement/prevention_and_management of_p.aspx (accessed 14 Jul 2013).

28. Fitch K, Bernstein SJ, Aguilar MD, et al. The RAND/UCLA Appropriateness Method User's Manual. 2001. http://www.rand.org/ pubs/monograph reports/MR1269.html (accessed 6 Jun 2013).

29. Rivara FP, Ennis SK, Mangione-Smith R, et al. Quality of care indicators for the rehabilitation of children with traumatic brain injury. Arch Phys Med Rehab 2012;3:381-5.

30. McAlindon TE, Bannuru RR, Sullivan MC, et al. OARSI guidelines for the non-surgical management of knee osteoarthritis. Osteoarthritis Cartilage 2014;22:363-88.

31. Basger BJ, Chen TF, Moles RJ. Validation of prescribing appropriateness criteria for older Australians using the RAND/UCLA appropriateness method. BMJ Open 2012;2:pii: e001431. http:// bmjopen.bmj.com/content/2/5/e001431.full (accessed 1 Jun 2013).

32. McGory ML, Kao KK, Shekelle PG, et al. Developing quality indicators for elderly surgical patients. Ann Surg 2009;250:338-47. 
33. Kravitz RL, Park RE, Kahan JP. Measuring the clinical consistency of panelists' appropriateness ratings: the case of coronary artery bypass surgery. Health Policy 1997;42:135-43.

34. Lave J, Wenger E. Situated learning: legitimate peripheral participation. Cambridge, UK: Cambridge University Press, 1991.

35. National Health and Medical Research Council. NHMRC additional levels of evidence and grades for recommendations for developers of guidelines. Stage 2 consultation. Early 2008_end June 2009. 2010. http://www.nhmrc.gov.au/_files_nhmrc/file/guidelines/stage_2 consultation levels and grades.pdf (accessed 2 Mar 2012).

36. Lanyon L, Rose M, Worrall L. The efficacy of outpatients and community aphasia groups. A systematic review. Int J Speech Lang Pathol 2013;15:359-74.

37. World Health Organisation (WHO). International classification of functioning, disability and health. Geneva, Switzerland: World Health Organisation, 2001. http://www.who.int/classifications/icf/en/ (accessed 14 Apr 2010).

38. Hersh D, Worrall L, Howe T, et al. SMARTER goal setting in aphasia rehabilitation. Aphasiol 2012;26:220-33.

39. Grimshaw JM, Eccles MP, Lavis JN, et al. Knowledge translation of research findings. Implement Sci 2012;7:50. http://www. implementationscience.com/content/7/1/50 (accessed 3 Sep 2012).

40. Stroke Foundation of New Zealand and New Zealand Guidelines Group. Clinical guidelines for stroke management 2010. Wellington: Stroke Foundation of New Zealand, 2010. http://www.health.govt.nz/ system/files/documents/publications/nzclinicalguidelinesstro kemanagement2010activecontents.pdf (accessed 5 Mar 2013).
41. Robey RR. A five-phase model for clinical-outcome research. J Comm Dis 2004;37:401-11.

42. Armstrong E, Hersh D, Hayward C, et al. Communication disorders after stroke in Aboriginal Australians. Disabil Rehabi 2014:1-8. Published Online First: 3 November 2014. doi:10.3109/09638288. 2014.972581

43. Armstrong E, Hersh D, Hayward C, et al. Living with aphasia: three Indigenous Australian stories. Int $J$ Speech Lang Pathol 2012;14:271-80.

44. Hersh D, Armstrong E, Panak V, et al. Speech-language pathology practices with Indigenous Australians with acquired communication disorders. Int J Speech Lang Pathol 2015; 17:74-85.

45. Pollock A, St George B, Fenton M, et al. Top ten research priorities relating to life after stroke. Lancet Neurol 2012;11:209. http://www. thelancet.com/journals/laneur/article/PIIS1474-4422(12)70029-7/ fulltext (accessed 28 Feb 2013).

46. Woolf $\mathrm{SH}$, Grol R, Hutchinson A, et al. Clinical guidelines: potential benefits, limitations, and harms of clinical guidelines. $B M J$ 1999;318:527-30.

47. Agency for Health Care Policy and Research. Using clinical practice guidelines to evaluate quality of care. Rockville, MD: US Department of Health and Human Services, Public Health Services. 1995.

48. Rose TA, Worrall LE, Hickson LM, et al. Guiding principles for printed education materials: design preferences of people with aphasia. Int J Speech Lang Pathol 2012;14:11-23. 